\title{
Should clinicians accept management responsibilities?
}

\author{
P.D. Welsby \\ Regional Infectious Diseases Unit, City Hospital, Greenbank Drive, Edinburgh EH10 5SB, UK
}

\begin{abstract}
Summary: The British National Health Service is changing and clinicians are being vigorously encouraged to accept managerial roles in addition to patient management.
\end{abstract}

Clinicians and health care managers have very different roles. Clinicians want to do the best they can for each patient whereas managers have a more difficult task as they have to organize clinical services to deliver the greatest good for the greatest number. Current financial constraints mean that clinical and management roles are bound to conflict. Clinicians will ask for more and more resources for patient care. There are four reasons for this. Firstly, technological developments will ensure dramatic increases in the cost of medical care. Secondly, each new and better drug which is developed increases the bill. Thirdly, new diagnostic developments will prove more expensive and wise bodies of doctors will recommend that today's expensive diagnostic tests are to be considered tommorrow's routine screening tests. Fourthly, surgical techniques will become more sophisticated and inevitably more costly. The managers, in contrast, will usually want to restrict expenditure: however, it is possible for clinicians and managers to disagree in a mature and even constructive (parliamentary) fashion.

\section{Effective management effectively means having budgetary responsibilities}

Health care has to be managed and budgetary allocations are a major tool to be used in this endeavour. I suggest that it is every clinician's responsibility to get as many resources as possible for his patients because clinicians, unlike managers, nave to keep faith with their individual patients and inevitably will tend to overspend budgets (Enoch Powell, when Minister of Health, realized this and concluded that the only way of limiting expenditure of a service that was free at the point of need was by having waiting lists). It is the managers' job to manage what they consider to be financially unrealistic demands of clinicians by identifying clearly the options for the public and the clinicians using the neglected 'if ... then' formula. 'If clinician $\mathrm{A}$ is allowed the resources requested, then clinician $B$ or some other service has to be denied.' 'If this district is to have an $X$ then it cannot have a $Y$ (to my mind one of the great weaknesses of modern managers is that they respond to requests for extra finance by stating 'there is not the money available' when everyone knows that money could be made available: the question is whether money should be made available).

In future managers will either have to accept escalating expenditure or restrict certain expensive treatment and procedures requested by clinicians for their patients. Because the government (the ultimate managers of a nationalized service) would rather do neither of these, it is not surprising that the British government is advocating a solution in which someone else has to issue the (financially limited) prescriptions - and this of course has to be clinicians, who, it is proposed, will be given budgetary responsibilities and thus the responsibility for allowing or refusing treatments to individual patients.

\section{Four reasons why clinicians should eschew budgetary roles}

Firstly, most clinicians are not trained in management (attendance at a few management courses is not adequate training) and many who have some experience of the problems managers face shy away from undertaking significant management roles. Most clinicians have trained for years to be clinically active and do not want to change their role in mid-life. It is true that some clinicians have achieved (admittedly sometimes evanescent) prominence by combining clinical and management roles but their degree of success is now being questioned and, even if successful, they are an atypical breed: many are workaholics who turn up to work before anyone else and leave after everyone else, and I doubt if the average clinician should attempt to compete: their families would probably be less than supportive!

Secondly, the extra workload and stresses for 
which budget-holding clinicians would have to assume responsibility include increased consumer expectations, ageing buildings, inflation, new and expensive high technology developments in health care, Government edicts and externally imposed pay awards, pressure groups, unions, new illnesses, expectations of Members of Parliament, media overreaction, and (not least) stroppy medical colleagues, whilst continuing their clinical responsibilities. It is ridiculous to imagine that there will be an appropriate increase in clinicians to cope with this extra increased managerial workload. Clinician managers may well be given partial financial responsibility but total blame if things go wrong.

Thirdly, if doctors are given budgets and have to reduce services to any group of patients for financial reasons, then they will then be perceived to be, quite literally, in business rather than in a caring profession.

Fourthly, the quintessential question for individ- ual patient care is whether consultants should only manage patients or whether better patient care would result if consultants were given the responsibility, authority and budgetary responsibility to manage their own units. But without many more $\stackrel{\rho}{\circ}$ clinicians with clinical and management training, I $\overline{0}$ fear that all clinician managers will gain is the blame for failing to control expenditure.

Reluctantly, I now feel that most clinicians $\underset{\otimes}{\overparen{D}}$ should resist extra non-clinical budgetary responsibility. If clinicians refuse to have budgetary responsibilities and insist that they be managed. (there can be no fudging this linkage), then they can $\overrightarrow{\vec{\omega}}$ unflinchingly look their patients in the eye and say $\stackrel{\sigma}{\sigma}$ 'I am doing the best I am allowed to do for you.' We $\bar{\square}$ should be looking after individual patients.

There is a decision to be made: clinicians should either attempt to manage or accept that they should be managed. 